Service social

\title{
L'adolescent et la loi concernant les jeunes contrevenants, Marie-Christine Barrette et al., Cowansville, Éditions Yvon Blais, 1994, 183 pages.
}

\section{François Marcotte}

Volume 43, numéro 3, 1994

Intervention individualisée et empowerment

URI : https://id.erudit.org/iderudit/706676ar

DOI : https://doi.org/10.7202/706676ar

Aller au sommaire du numéro

Éditeur(s)

École de service social de l'Université Laval

ISSN

1708-1734 (numérique)

Découvrir la revue

Citer ce compte rendu

Marcotte, F. (1994). Compte rendu de [L'adolescent et la loi concernant les jeunes contrevenants, Marie-Christine Barrette et al., Cowansville, Éditions Yvon Blais, 1994, 183 pages.] Service social, 43(3), 158-159.

https://doi.org/10.7202/706676ar d'utilisation que vous pouvez consulter en ligne.

https://apropos.erudit.org/fr/usagers/politique-dutilisation/ 


\section{L'ADOLESCENT ET LA LOI CONCERNANT LES JEUNES CONTREVENANTS}

Marie-Christine Barrette et al.

Cowansville, Éditions Yvon Blais, 1994, 183 pages.

Récipiendaire du prix Charles-Coderre en 1993, cet ouvrage réunit les trois meilleurs essais soumis par des étudiants en droit d'universités québécoises au concours annuel de la Fondation Charles-Coderre, qui se consacre à l'avancement du droit social. Les travaux de recherche devaient porter sur I'application de la Loi sur les jeunes contrevenants. La problématique imposée aux étudiants orientait leurs travaux de recherche vers des questions précises, telles que: les caractéristiques fondamentales du système pénal juvénile qui distinguent celui-ci du système adulte ; l'esprit de la Loi en matière de protection de la société et de réponse aux besoins spéciaux de l'adolescent contrevenant; la compatibilité ou non de ces deux objectifs dans les décisions que doit rendre le Tribunal; et enfin, ils devaient conclure en portant un jugement sur l'utilité de la Loi et son efficacité à la lumière de l'expérience américaine.

Les trois études publiées reprennent chacune à leur façon l'analyse de ces questions, qui constituent la matière de ce livre. La première étude, menée par trois étudiantes de l'Université de Sherbrooke, commence par illustrer les différences bien réelles du système pénal pour adolescents comparé au système criminel adulte. Elles relèvent huit caractéristiques distinctes, allant de l'implication des parents dans le processus judiciaire à l'existence d'un programme de mesures de rechange et à l'obligation faite au juge de tenir compte des besoins de l'adolescent dans ses décisions. Elles passent ensuite à l'analyse critique des principes directeurs de la Loi, tels qu'énoncés à l'article 3, et s'attardent au dilemme engendré par les objectifs simultanés de "protection de la société » et de "réponse aux besoins de l'adolescent "visés par le législateur. Elles font observer I'imprécision de la loi, son ambiguïté à ce niveau, car «le juge doit-il considérer simultanément les deux points de vue ou doit-il, au contraire, en privilégier un au détriment de l'autre? La législation actuelle ne permet pas de répondre de façon catégorique à cette interrogation» (p. 22). De là I'hypothèse qu'il faut rechercher un équilibre constant entre ces deux notions; toutefois, s'appuyant sur la doctrine et la jurisprudence, elles démontrent "qu'en raison du manque de clarté du législateur», la préséance de la protection de la société ou des besoins du jeune est finalement liée au rôle de chacun des intervenants, à ses convictions et valeurs personnelles, ce qui confère à la Loi sur les jeunes contrevenants une certaine faiblesse en matière $d^{\prime}$ 'uniformité pénale. Le dilemme reste donc entier. En pratique, notent-elles, on parvient à préserver un certain équilibre, car l'avocat de la défense insiste sur les droits et besoins de son client, le procureur de la Couronne vise à protéger la société et le juge est appelé à rendre une décision qui concilie tous ces principes. 
Malgré cette limite, les auteures reconnaissent plusieurs qualités qui confirment le bien-fondé et la pertinence de cette loi, «car un système de justice pour adolescents axé sur la réhabilitation et la responsabilité des contrevenants est certainement la meilleure manière de prévenir la criminalité» (p. 34). Ayant comparé succinctement la législation canadienne à celle en vigueur dans deux États américains, I'une étant d'inspiration humaniste et libérale (État du Massachusetts), I'autre plus conservatrice et axée sur la punition (État de New York), les auteures sont d'avis que les systèmes plus répressifs ne donnent pas de meilleurs résultats. Une approche fondée sur la réhabilitation est encore préférable, malgré la revendication de peines plus sévères par le public qui a plus ou moins perdu confiance dans notre système.

La deuxième étude, rédigée en anglais et menée par un étudiant de I'Université d'Ottawa, intègre les approches canadiennes et américaines dans le traitement des jeunes contrevenants. Elle met en relief qu'il existe de nombreuses similitudes entre le «Federal Juvenile Delinquency Act» de nos voisins du sud et la loi canadienne, même si chaque État dispose d'une certaine latitude dans l'administration de la justice des mineurs. S'attardant sur la pratique dans l'État de New York, I'auteur observe lui aussi que la plus grande sévérité destinée à protéger la société dans un contexte de violence urbaine $n^{\prime}$ atteint pas l'effet attendu de prévenir la récidive ni de diminuer la quantité de crimes juvéniles.

Provenant de l'Université de Montréal, la troisième recherche expose les étapes du processus judiciaire dans le traitement d'une plainte. Les intervenants expérimentés et au fait de la loi n'apprendront rien de bien neuf dans cette partie, qui est la plus faible de l'ouvrage. Les auteures font toutefois une analyse soignée des amendements de 1992, ce que les autres étudiants ne font pas. Ce chapitre intéressera davantage les néophytes.

Dans l'ensemble, il s'agit d'un ouvrage rigoureux, riche et bien documenté, comportant une bibliographie et des annexes à la fin de chaque section. L'inconvénient principal est lié à la formule du concours, ce qui donne lieu à des répétitions d'un chapitre à l'autre. L'intérêt principal de cet ouvrage est surtout l'actualité de son sujet: dans un contexte où le public canadien et certains médias réclament plus de sévérité de la part des tribunaux juvéniles et même un durcissement de la Loi, les auteures invitent à la nuance et à la prudence face à des jugements hâtifs et fondés sur l'émotion. Et elles concluent généralement que ce n'est pas tant la Loi elle-même qui est à critiquer - sauf à l'égard des récidivistes pour lesquels le renvoi aux tribunaux adultes n'est pas assez utilisé à leur avis -, que la façon dont elle est gérée et appliquée. Voilà une opinion qui sera partagée par plusieurs intervenants socio-judiciaires québécois. 